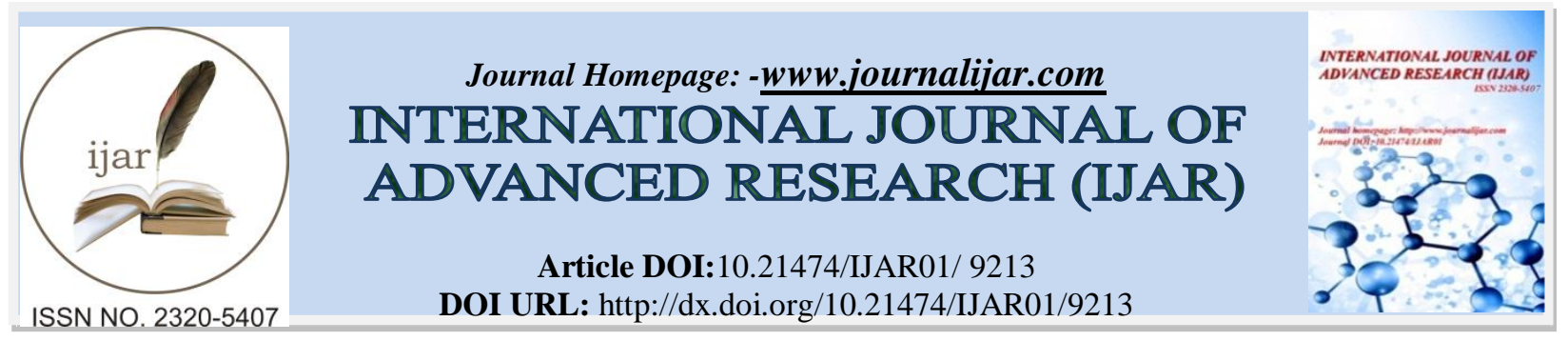

\title{
RESEARCH ARTICLE THE BENEFITS OF RELAXATION EXERCISE FOR CHRONIC COLITIS.
}

\author{
Amany E. Abd El-Tawab, Rawapy S. Alsarrah and Shatha S. Al haboob
}

Department of Physical Therapy and Health Rehabilitation, College of Applied Medical Sciences, Jouf University.

\section{Manuscript Info}

..........................

Manuscript History

Received: 05 April 2019

Final Accepted: 07 May 2019

Published: June 2019

Key words:-

colitis, relaxation, colon pain, adolescent.

\section{Abstract}

Background: Inflammatory bowel diseases are a group of inflammatory conditions in which the body's own immune system attacks parts of the digestive system. Crohn's disease and chronic colitis cause chronic inflammation of the gastrointestinal tract.

Objective: This study investigated evidence for the use of relaxation therapies as interventions to decrease inflammatory bowel diseases symptoms and severity as well as reduce anxiety and improve quality of life in chronic colitis patients.

Methods: A search of electronic bibliographic databases was conducted to identify randomized controlled trials that included relaxation exercise programs for patients with chronic colitis. Progressive muscle relaxation technique was used to case group. Meanwhile dietary regulation group was used for control one and all studies were used in the static-analysis.

Results: The results showed that the mean age of participant was $23 \pm 3$ years, mean weight was $58 \pm 7 \mathrm{~kg}$ and mean height was $158 \pm 3$ meter. The results of our study revealed that there was not significant differences between group $(\mathrm{p}>0.05)$ pretreatment in the mean value total score of clinical activity for the evaluation of patients with chronic colitis. The mean of the total score post treatment was $3.60 \pm 0.69$ in case group and was $4.80 \pm 1.13$ in control group. The different between groups was significant $(\mathrm{p}<0.05)$.

Conclusion: The current study demonstrated that there was a highly positive effect of relaxation exercise and dietary regulation in reducing colon pain. Further studies are needed to ascertain the long-term effects of relaxation therapy and the underlying psychosocial mechanisms, larger sample size, male group, different areas, different categories of age leading to anxiety reduction and improved quality of life.

Copy Right, IJAR, 2019,. All rights reserved.

\section{Introduction:-}

The colon is a capacious tube that roughly surrounds the loops of small intestine as an arch. Named from the Greek koluein ("to retard"), the colon is variable in length, averaging approximately $150 \mathrm{~cm}$, which corresponds to onequarter the length of the small intestine. Its diameter can be substantially augmented by distension, it gradually decreases from $7.5 \mathrm{~cm}$ at the cecum to $2.5 \mathrm{~cm}$ at the sigmoid. In humans, the colon is described to be somewhere between the short, straight type with a rudimentary cecum (Jorge andHabr-Gama, 2003).

Corresponding Author: - Amany E. Abd El-Tawab.

Address:-Department of Physical Therapy and Health Rehabilitation, College of Applied Medical

Sciences, Jouf University. 
Inflammatory bowel disease (IBD) encompasses several chronic inflammatory conditions, most significantly chronic colitis (CC) and Crohn's disease (CD). While these two conditions share many common features - diarrhea, bloody stools, weight loss, abdominal pain, fever, and fatigue (Headand and Jurenka, 2003). Crohn's disease may involve the entire GI tract and chronic colitis involves only the large intestine (Yeh et al. 2017).

Chronic colitis is a chronic inflammatory disease affecting the colon, and its incidence is rising worldwide. The pathogenesis is multifactorial, involving genetic predisposition, epithelial barrier defects, dysregulated immune responses, and environmental factors. Patients with chronic colitis have mucosal inflammation starting in the rectum that can extend continuously to proximal segments of the colon. chronic colitis usually presents with bloody diarrhea and is diagnosed by colonoscopy and histological findings. The aim of management is to induce and then maintain remission, defined as resolution of symptoms and endoscopic healing (Ungaro et al. 2017).

Chronic colitis only affects the colon and it is typically confluent so it can be recognised by a continuous inflammation in the bowel that then has a clear cut-off (Danese et al. 2015). At present, in the UK around one in every 650 people will develop Crohn's disease and one in 420 will develop ulcerative colitis, and although either condition can develop at any age there has been a recent increase in the number of children diagnosed (Crohn's and Colitis, 2016).

$\mathrm{CD}$ is a chronic progressive disease inducing cumulative structural damage. At 2011 study by Pariente et al. (2011) showed that with time CD patients are more likely to develop strictures, fistulae/abscesses, and undergo surgery. Desired outcomes differ between early and late stage CD. For early disease, they include complete absence of symptoms, no disease progression, no complications or disability, and normal quality of life (QoL), while for latestage disease they include stabilisation of non-inflammatory symptoms progression of damage or disability, and improved QoL (Panaccione and Dotan. 2017).

The pathogenesis of chronic colitis involves a complex interplay of a dysregulated immune response to an unknown environmental stimulus or dysbiosis in the colon in a genetically susceptible host (Loftus, 2004). There is increasing evidence to suggest that the intestinal microflora may play an important role in the pathogenesis of chronic colitis (Dupaul-Chicoine and Saleh , 2013). Previous studies report an increased risk of occurrence and exacerbation of IBD following gastrointestinal (GI) infections with enteropathogenic bacteria (Nielsen et al. 2009).

Stress induces changes in GI function, such as increased intestinal permeability and visceral sensitivity, and altered GI gut motility, which could lead to IBD symptoms. Especially early life stress, such as maternal separation, has a large impact on inflammation, intestinal barrier function and dysfunction of the hypothalamic-pituitary-adrenal (HPA) axis in rodents and animals (Holgersen et al. 2014).

Early treatment of chronic colitis is key for achieving the therapeutic goals, which include symptomatic remission and mucosal healing. Integrative medicine is considered a healing-oriented medicine that reaffirms the importance of the relationship between practitioner and patient, focuses on the whole person, and utilizes empirically supported therapeutic approaches. According to the National Institute of Health, integrative medicine is an umbrella term that can include various modalities such as natural products (e.g., herbs and supplements), and mind-body interventions (Cheifetz et al. 2017). Protective factors, such as physical activity (PA), with gastrointestinal diseases risk and prognosis is of high relevance in the global battle against disease (Washington, 2007).

The relationship between stresses, emotional distress, and negative IBD-related outcomes, researchers have explored the efficacy of relaxation and stress-management protocols for IBD patients. The goal of such interventions is to teach patients skills to relax and reduce daily stress in order to support improved psychological and physical wellbeing. The content of these interventions varies, as well as the format, delivery and duration (Yeh et al. 2017).

Relaxation-based interventions usually focus on teaching patients a subset of relaxation strategies, such diaphragmatic breathing techniques, guided imagery, progressive muscle relaxation) (e.g., focus on building and releasing muscle tension), and autogenic training (i.e., focus on physical manifestations of relaxation in the body like heaviness in the musculoskeletal system or warmth of the circulatory system) (Timmer et al. 2011).

Stress management protocols tend to include psycho education (e.g., related to IBD and treatment; stress and relaxation response) and a variety of relaxation and coping skills (e.g., problem solving, communication, identifying and modifying negative thoughts). Exercise and diet support are also integrated into some stress management 
treatments (Knowles et al. 2017). The majority of research investigating the use of relaxation and stress management interventions in IBD populations has been conducted in adult samples.

\section{Objectives:-}

The aim of the present study is to evaluate the benefits of relaxation exercise for chronic colitis in the students of Jouf University.

\section{Hypothesis (alternative hypothesis):}

There is a significant effect of relaxation exercise on chronic colitis.

\section{Limitation:}

Limitation of the study are:

1. Session time and repetition

2. Psychological condition

3. Functional variation between cases

4. Sample was selected only from Jouf university

\section{Delimitation:}

Delimitation of this study are:

1. Measurement of clinical activity for the evaluation of patients with chronic colitis for case and control group.

2. Measurement of clinical activity for the evaluation of patients with chronic colitis pre and post treatment.

3. Comparison between case and control groups in the percentage and total scores of clinical activity for the evaluation of patients with chronic colitis

4. Evaluation sheet that it was specified for each case.

\section{Materials and Methods:-}

This study was carried out to investigate the benefits of relaxation exercise for chronic colitis. This study was conducted at physical therapy laboratory at faculty of applied medical science, jouf University. This study was conducted for four weeks of total twenty sessions with an average five times per week. The average time for each session was fifteen up to twenty minutes.

\section{Subjective selection:}

Twenty female participants were volunteered to participate in this study. They were randomly selected from the university and divided into two groups. All subject were in good health. They were recruited from community by advertisement diagnosed with chronic colitis. Two study samples groups has been used one control and other case group.

\section{The subjects meet the following criteria:}

\section{Inclusion criteria are:}

1. Height: ranged from 160 to $170 \mathrm{~cm}$

2. Weight: ranged from 60 to $80 \mathrm{~kg}$

3. Age: ranged from 15 to 30 years old

\section{Exclusion criteria are:}

1. Major surgical operation

2. Patient with epilepsy

Instrument and equipment:

1. Body height and weight scale: used to measure height in centimeter and mass of the body in kilogram.

2. Clinical activity for the evaluation of patients with chronic colitis: is questionnaire design to demonstrate clinical activity for the evaluation of patients with chronic colitis. This clinical activity for the evaluation of patients with chronic colitis composes of nine sections each section is varied between two to six questions. The percentage was varied between $22 \%$ up to $59 \%$ pre treatment and it was varied between $9 \%$ up to $27 \%$ post treatment.

3. Comfortable sitting chair. 


\section{Procedure:}

The height was measured for each participant in meter and weight was also measured in kilogram used mechanical height and weight scale in standing position, the measurement were done according to standard procedure.

\section{Technique:}

Progressive muscle relaxation technique and dietary regulation were used to case group. Meanwhile dietary regulation was used only for control one.

\section{Progressive muscle relaxation technique:}

It involves the following steps:

This method of relaxation focuses on the tensing and then relaxing of the various muscle groups. When used in combination with abdominal breathing, this method of relaxation can have profound effects on one's level of tension and anxiety by promoting a state of deep relaxation.

This exercise may take approximately 20-25 minutes to complete. Although this may feel like a significant time commitment, keep in mind the positive results you will experience when you give yourself permission to take this personal time. Allow yourself to put aside your worries during this time, realizing you can always return to them later.

1. To begin, find a comfortable space where you can sit or lie down and where you are free from distractions. Take 3-4 deep abdominal breaths, inhaling and exhaling slowly and rhythmically as discussed above. You may wish to close your eyes for this exercise.

2. Begin by tensing the muscles in your forehead, making a frown. Hold this for 3-4 seconds and release the tension. Notice the difference in sensation between the tensing and relaxing of these muscles.

3. Next, squeeze your eyelids together for the same count. Hold and release the tension, letting your eyelids become heavy and relaxed.

4. Wrinkle your nose for several seconds. Hold and relax.

5. Move to your jaw. Tense, hold and relax these muscles.

6. Allow all of the muscles in your face to relax. Imagine the tension draining away. Take a nice, deep breath in and then out.

7. Next, move to the muscles in your neck. Slowly roll your head from one side to the other. Reverse directions and do this again. Imagine your neck muscles feeling loose and relaxed.

8. Shrug your shoulders, bringing them up tightly toward your ears. Hold for a count of three and then relax them.

9. Move to your upper and lower arms and fists, tightening and then releasing the tension. Allow your arms and hands to hang limply by your side. Feel the tension draining from your shoulders through your arms and hands.

10. Take another slow, deep breath inward and tighten your abdominal muscles. Hold this for three counts and then slowly exhale, focusing on the warmth and positive sensation you are feeling.

11. Next, focus on tensing your upper legs. Hold and then release the tension. Slowly move to your lower legs and calf muscles. Again, hold and release. Now move to your feet and ankles. Point your toes toward you, hold and then release. Circle your ankles in both directions, releasing any tension you may be feeling in this area.

12. Now take 2-3 slow, deep breaths. Scan your body to see if there are any areas where you are still feeling tension. If there are, direct your attention to these areas, tensing and relaxing them as you have just done. Imagine the tension being completely drained, leaving you feeling a sense of warmth and heaviness.

Enjoy this feeling of relaxation for several minutes. Allow yourself 3-4 deep abdominal breaths before resuming your breathing to its normal pace. When you are ready, open your eyes, stretch, and reorient yourself to your surroundings.

You may want to tape the above exercise on an audiocassette to help guide you through it. As it was stated above, it is best to practice the exercise on a daily basis to gain its full benefits. As you become more familiar with the exercise, you may find you are able to complete it in 20 minutes or less (Zeichner, 2018). 
1. Sit on a chair.

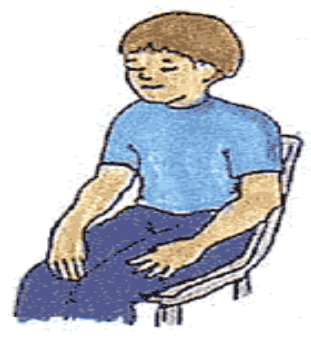

3. Tense your arms Count to 3

1,2,3..

Take a deep breath and relax.

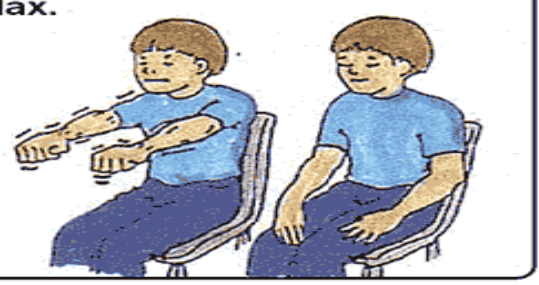

5. Tense your legs. Count to 3 .

$1,2,3 \ldots$

Take a deep breath.

Relax.

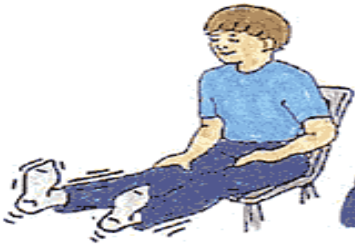

2. Scrunch your face. Count to 3 .

$1,2,3 \ldots$

Take a deep breath.

Relax.

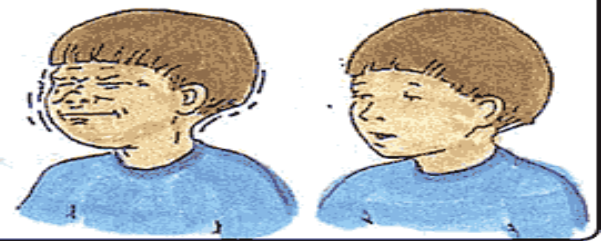

4. Tense your arms and shoulders. Count to 3 .

$1,2,3 \ldots$

Take a deep breath.

Relax.

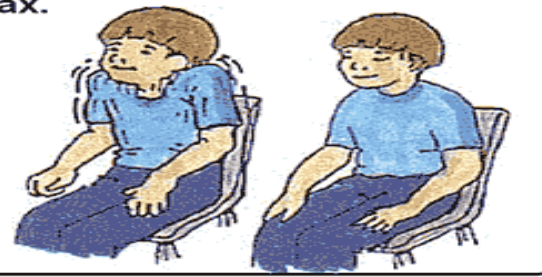

6. Breathe in relaxation breathe out tension.

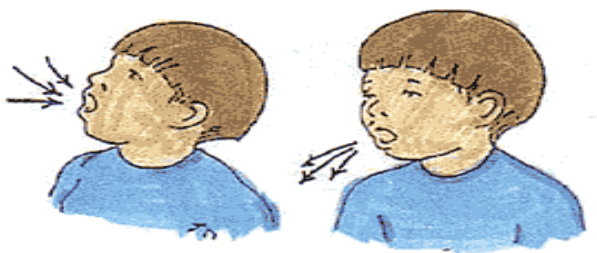

Figure 1:-show the Progressive muscle relaxation

Table 1:-Dietary regulation table involve (Feagins etal. 2014)

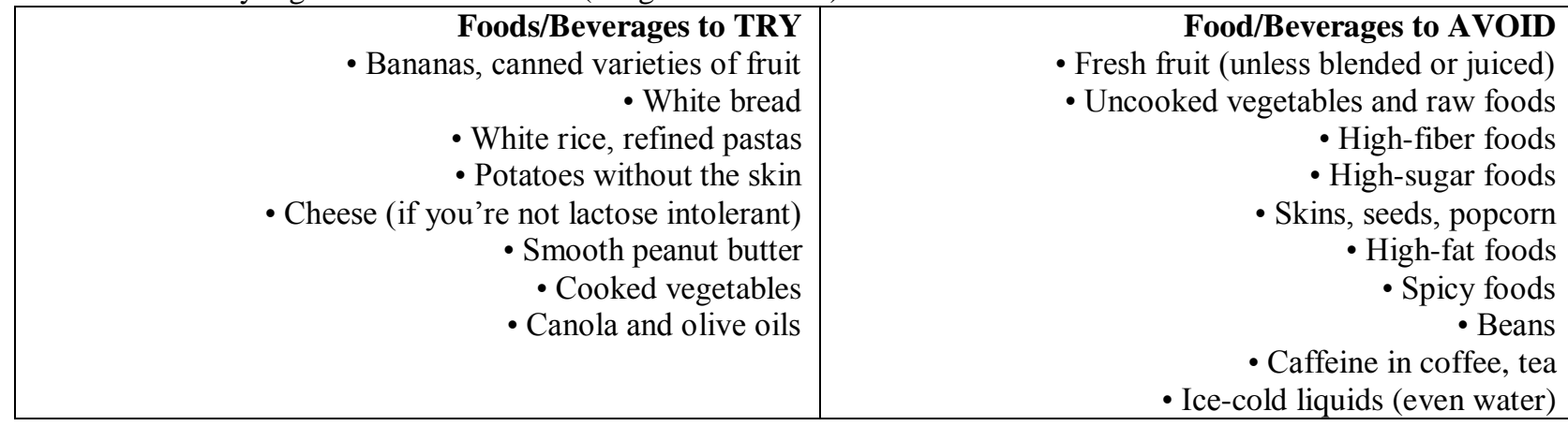

\section{Study Design:}

Case-control study was used to assess benefits of relaxation exercise on chronic colitis.

\section{Data Analysis:}

Data collect and computerized using SPSS program (Statistical Package of Social Science) program, version 22 and Excel application (2010).Independent t-test was used to compare between case and control groups in the mean differences clinical activity for the evaluation of patients with chronic colitis. Moreover, paired sample t test was also used to compare within each group. Level of significance chosen was 0.05 . 


\section{Results:-}

The mean age of participant was $23 \pm 3$ years and mean weight was $58 \pm 7 \mathrm{~kg}$. The mean height was $158 \pm 3$ centimeter, the characteristics of the subject represented in the table (2) and demonstrated in figure (2).

Table 2:-Descriptive statistics for the subjects

\begin{tabular}{|l|c|c|}
\hline \multicolumn{1}{|c|}{ Characteristics } & Mean & STD. deviation \\
\hline Age (years) & $\mathbf{2 3}$ & $\pm \mathbf{3}$ \\
\hline Weight (kg) & $\mathbf{5 8}$ & $\pm \mathbf{7}$ \\
\hline Height $(\mathbf{m})$ & $\mathbf{1 5 8}$ & $\pm \mathbf{3}$ \\
\hline
\end{tabular}

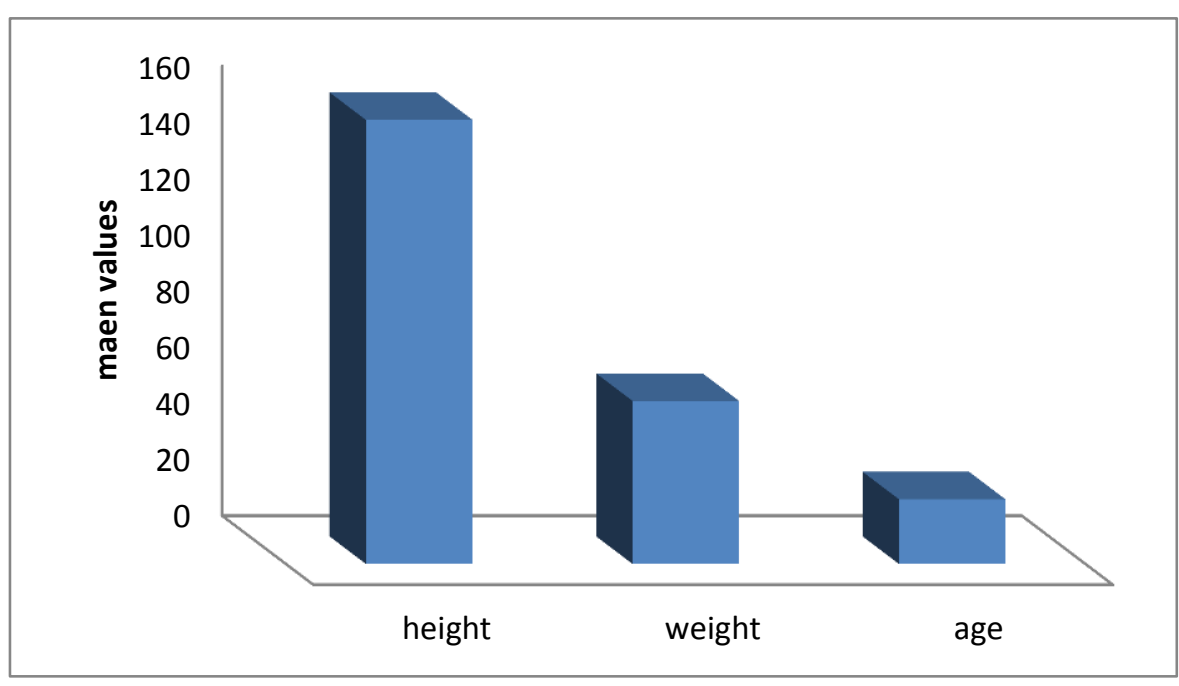

Figure 2:-characteristic of subjects

The mean of the total score of clinical activity for the evaluation of patients with chronic colitis pretreatment was 8.5 \pm 1.84 in case group and was $10 \pm 2.49$ in control group. The different between groups was not significant $(\mathrm{p}>$ 0.05).The mean of the total score of clinical activity for the evaluation of patients with chronic colitis post treatment was $3.60 \pm 0.69$ in case group and was $4.80 \pm 1.13$ in control group, the different between groups was significant $(\mathrm{p}$ $<0.05)$.

The mean of the percentage of clinical activity for the evaluation of patients with chronic colitis retreatment was $38.20 \pm 8.45$ in case group and was $45 \pm 11.45$ in control group. The different between groups was not significant ( $>0.05$ ). The mean of the percentage clinical activity for the evaluation of patients with chronic colitis post treatment was $16.10 \pm 3.24$ in case group and was $21.30 \pm 5.05$ in control group. The different between groups was significant $(\mathrm{p}<0.05)$.

Table 3:-Descriptive statistics using independent sample $\mathrm{T}$ test for two groups

\begin{tabular}{|r|c|c|c|c|}
\hline \multicolumn{1}{|c|}{ GROUP } & Mean & STD.DEVIATION & T VALUE & P VALUE \\
\hline PINPRE & & & -1.51 & 0.14 \\
Case & 38.20 & 8.45 & & \\
Control & 45.00 & 11.45 & $2.73-$ & $0.014^{*}$ \\
PINPOST & & & & \\
Case & 16.10 & 3.24 & $1.53-$ & 0.14 \\
Control & 21.30 & 5.05 & & \\
\hline TSINPRE & & & & $0.011^{*}$ \\
Case & 8.50 & 1.84 & $2.48-$ & \\
Control & 10.00 & 2.49 & & \\
\hline TSINPOST & & 0.69 & & \\
Case & 3.60 & 1.13 & & \\
control & 4.80 & & & \\
\hline
\end{tabular}

*Significant difference 


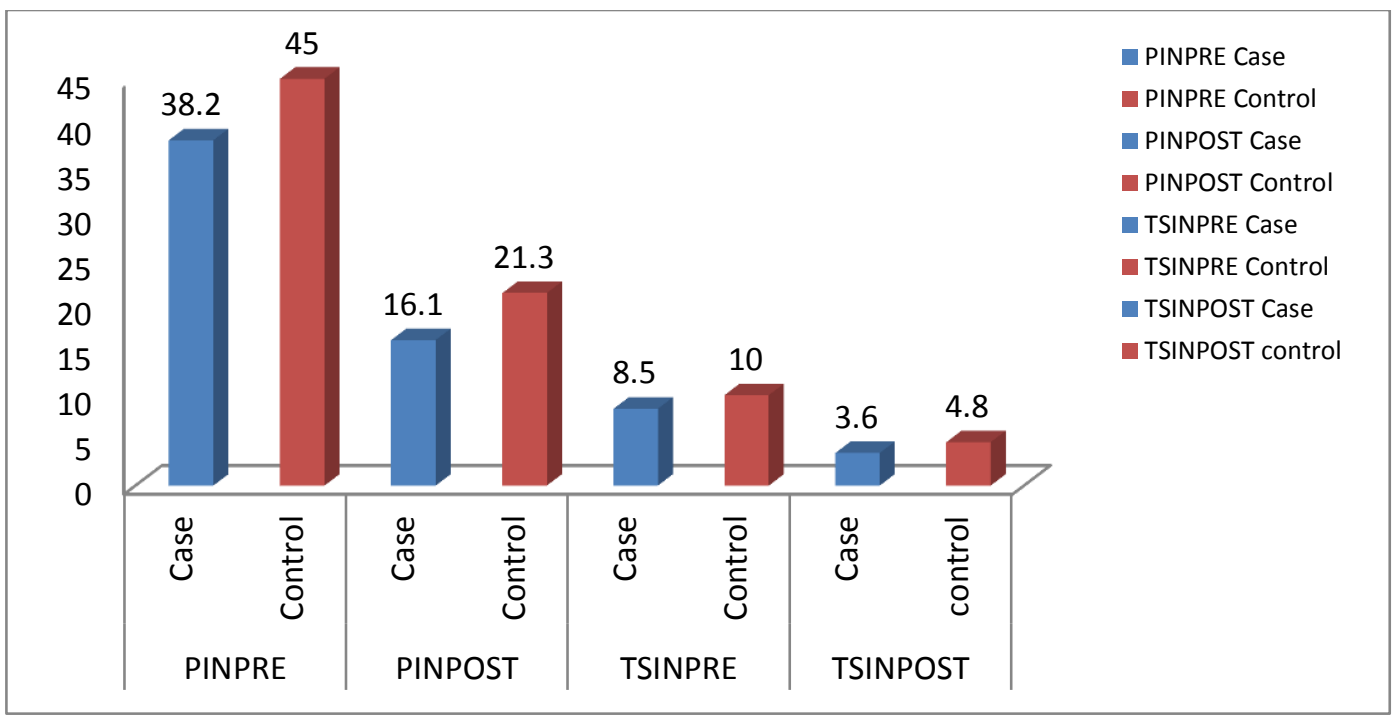

Figure 3:-descriptive statistics using independent sample $\mathrm{T}$ test for case and control group.

Using paired sample t test to compare within each group. It was revealed that there were highly significant differences in the mean values of percentage and total score clinical activity for the evaluation of patients with chronic colitis pre and post treatment for the case and control groups.

Table 4:-Different in mean value of clinical activity for the evaluation of patients with chronic colitis score and percentage for Case group

\begin{tabular}{|l|c|c|c|c|}
\hline GROUP & MEAN & SD & T value & P value \\
\hline $\begin{array}{l}\text { Pair } 1 \\
\text { PINPRE - PINPOST }\end{array}$ & 22.10 & 8.19 & 8.52 & $0.000^{*}$ \\
\hline $\begin{array}{l}\text { Pair } 2 \\
\text { TSINPRE- TSINPOST }\end{array}$ & 4.90 & 1.79 & 8.64 & $0.000^{*}$ \\
\hline
\end{tabular}

*Significant difference

Table 5:-Different in mean value of clinical activity index for the evaluation of patients with chronic colitis score and percentage for control group

\begin{tabular}{|l|r|r|r|c|}
\hline \multicolumn{1}{|c|}{ GROUP } & \multicolumn{1}{|l|}{ MEAN } & \multicolumn{1}{l|}{ SD } & \multicolumn{1}{l|}{ T value } & \\
\hline $\begin{array}{l}\text { Pair 1 } \\
\text { PINPRE - PINPOST }\end{array}$ & 23.70 & 7.52 & 9.95 & $0.000^{*}$ \\
\hline $\begin{array}{l}\text { Pair 2 } \\
\text { TSINPRE- TSINPOST }\end{array}$ & 5.20 & 1.61 & 10.15 & $0.000^{*}$ \\
\hline
\end{tabular}

*Significant difference 


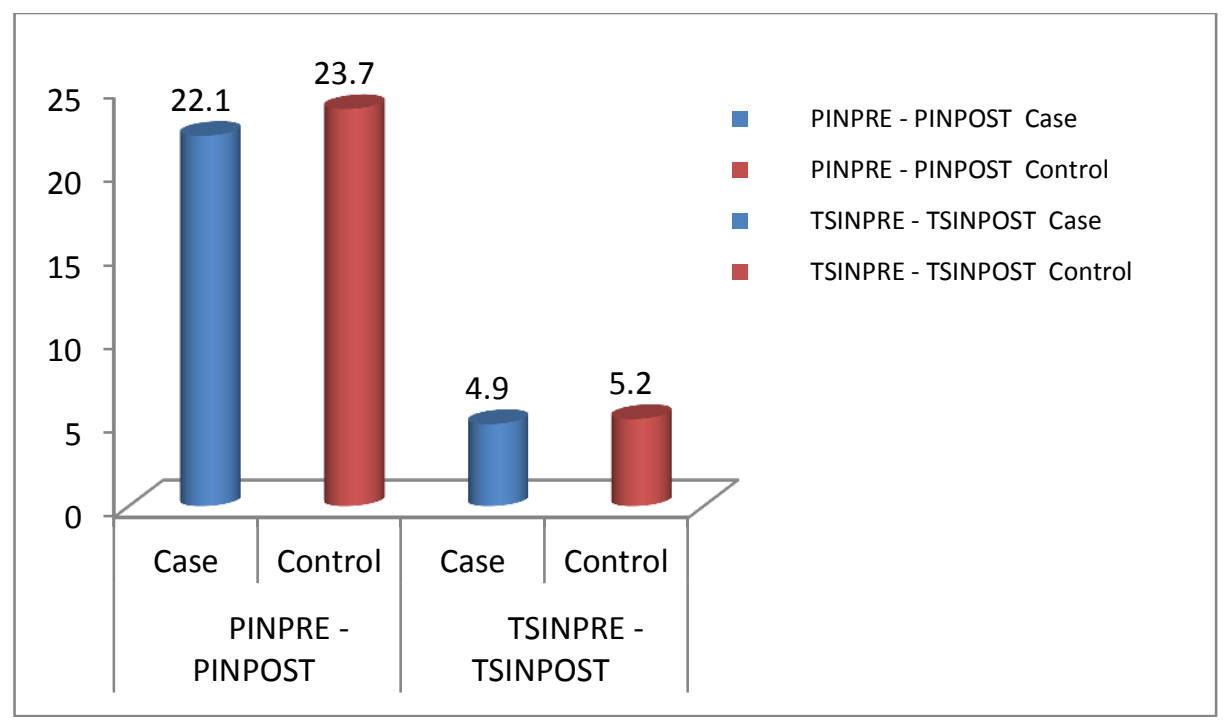

Figure 4:-Different in mean value in clinical activity for the evaluation of patients with chronic colitis score and percentage for Case and control group

\section{Discussion:-}

The results of our study revealed that there was not significant differences between group $(\mathrm{p}>0.05)$ pretreatment in the mean value total score of clinical activity for the evaluation of patients with chronic colitis. The mean value of the total score of clinical activity for the evaluation of patients with chronic colitis post treatment was $3.60 \pm 0.69$ in case group and was $4.80 \pm 1.13$ in control group. The different between groups was significant $(\mathrm{p}<0.05)$.

The mean of the percentage of clinical activity for the evaluation of patients with chronic colitis pre treatment was $38.20 \pm 8.45$ in case group and was $45 \pm 11.45$ in control group. The different between groups was not significant $(\mathrm{p}>0.05)$. The mean of the percentage of clinical activity for the evaluation of patients with chronic colitis post treatment was $16.10 \pm 3.24$ in case group and was $21.30 \pm 5.05$ in control group , The different between group was significant $(\mathrm{p}<0.05)$

However, It was concluded by Blanchard et al. (1992).It is clear from the above discussion that studies of each of the individual psychologic interventions appear to yield positive treatment effects. This is also the general conclusion of several systematic reviews that have examined the overall psychologic treatment literature in IBS. For example, a recent meta-analysis of controlled trials of psychologic treatments for IBS (Lackner et al., 2004) concluded that psychologic treat 'Behavioral therapy is more effective than placebo at relieving individual IBS symptoms'. Several other reviews have also concluded that psychologic interventions are generally effective although not universally so(Lea and Whorwell, 2004).

Normal treatment for irritable bowel syndrome revolves around dietary changes, nutritional supplements, stress avoidance and medications. Doctors and dietitians can help you if you have symptoms of this disorder, which include abdominal pain, gas, constipation and diarrhea. Four relaxation techniques that reduce general anxiety and stress may help alleviate IBS symptoms and make your life easier (Minesh. 2018).

Although there have been many successful, controlled demonstrations of the clinical efficacy of multi component treatments for irritable bowel syndrome (IBS), in the present study we sought to evaluate a single component of many of these regimens, relaxation training. Eight IBS patients received a 10-session (over 8 weeks) regimen of abbreviated progressive muscle relaxation with regular home practice while 8 comparable patients merely monitored GI symptoms. Based on daily GI symptom diaries collected for 4 weeks before and 4 weeks after treatment (or continued symptom monitoring), the Relaxation condition showed Significantly $(\mathrm{p}=.05)$ more improvement on a composite measure of primary GI symptom reduction than the Symptom Monitoring condition. Fifty percent of the Relaxation group were clinically improved at the end of treatment (Blanchard et al., 1993). 
Methods a search of electronic bibliographic databases (e.g., Medline Ovid, Embase, KoreaMed, and National Discovery for Science Leaders) was conducted to identify randomized controlled trials that included relaxation exercise programs for adults (>18 years old) with IBS. Of the 486 publications identified, 8 studies met inclusion and exclusion criteria, and all studies were used in the meta-analysis. We used Cochrane's risk of bias to assess study quality.

Moreover, Schumann et al.(2016) supported our results. His study involved six randomized controlled trials with a total of 273 patients were included in the qualitative analysis. There was evidence for a beneficial effect of a yogic intervention over conventional treatment in IBS, with significantly decreased bowel symptoms, IBS severity, and anxiety. Furthermore, there were significant improvements in quality of life, global improvement, and physical functioning after yoga compared with no treatment. Two randomized controlled trials reported safety data stating that no adverse events occurred. Overall, risk of bias of the included studies was unclear.

However, our results were opposed by Parket et al. (2014). They revealed that IBS symptoms decreased significantly, and there was no heterogeneity. Symptom severity and anxiety decreased due to relaxation therapies, however theses scores were not statistically significant.

\section{Recommendation and future researches:}

It is recommended to apply the same study on:

1. larger sample size

2. male group

3. different areas

4. different categories of age

5. varied clinical disease (disorders)

\section{Conclusion:-}

The current study demonstrated that there was a highly positive effect of relaxation exercise and dietary regulation in reducing colon pain.

\section{References:-}

1. Blanchard EB, Schwarz SP, Suls JM, Gerardi MA, Scharff L, Greene B. Two controlled evaluations of multicomponent psychological treatment of irritable bowel syndrome. Behav Res Ther 1992; 30:175-89.

2. Blanchard, E,Greene, B, Scharff L, Schwarz-McMorris SP. Relaxation training as a treatment for irritable bowel syndrome. Biofeedback Self Regul. 1993; 18(3):125-32.

3. Cheifetz, A.S.; Gianotti, R.; Luber, R.; Gibson, P.R. Complementary and Alternative Medicines Used by Patients with Inflammatory Bowel Diseases. Gastroenterology, 2017:152, 415-429.

4. Danese $\mathrm{S}$, et al. Development of red flags index for early referral of adults with symptoms and signs suggestive of Crohn's disease: An IOIBD Initiative. J Crohn's and Colitis,2015: 9(8):601-6.

5. Feagins,A.; Rashid,F.; Szigethy,E. Inflammatory Bowel Disease and Irritable Bowel Syndrome Similarities and Differences.Nestle Health Science Company,2014:1-12

6. Head, K. and Jurenka, J. Inflammatory Bowel Disease Part I: Ulcerative Colitis - Pathophysiology and Conventional and Alternative Treatment Options. Altern Med Rev;2003, 8(3):247-283

7. Holgersen, K.; Kvist, PH.; Markholst, H.; Hansen, AK. And Holm, TL. Characterisation of enterocolitis in the piroxicam-accelerated interleukin-10 knock out mouse - a model mimicking inflammatory bowel disease. J Crohns Colitis,2014, 8(2):147-60.

8. Jorge,J. and Habr-Gama,A. (2003): Anatomy and Embryology of the Colon, Rectum, and Anus.

9. Knowles, S.R.; Monshat, K. and Castle, D.J. The efficacy and methodological challenges of psychotherapy for adults with inflammatory bowel disease: A review. Inflamm. Bowel Dis., 19,2017,2704-2715.

10. Lackner JM, Mesmer C, Morley S, Dowzer C, Hamilton S. Psychological treatments for irritable bowel syndrome: a systematic review and meta-analysis. J Consult Clin Psychol 2004; 72:1100-13.

11. Lea R, Whorwell PJ. Psychological influences on the irritable bowel syndrome. Minerva Med 2004; 95:443-50.

12. Loftus, E.V. Clinical epidemiology of inflammatory bowel disease: Incidence, prevalence, and environmental influences. Gastroenterology, 2004,126:1504-17.

13. Nielsen, H. Gradel, K.;Schønheyder, HC.et al. Increased short- and long-term risk of inflammatory bowel disease after salmonella or campylobacter gastroenteritis. Gastroenterology, 2009:137:495-501. 
14. Panaccione, R. and Dotan, I. TARGETING DISEASE PROGRESSION IN CROHN'S DISEASE: FIGHTING AN UNRELENTING ENEMYEMJ Gastroenterol. 2017; 6:11-18.

15. Pariente, B. et al. Development of the Crohn's disease digestive damage score, the Lémann score. Inflamm Bowel Dis.;2011, 17(6):1415-22.

16. Park, S. H., Han, K. S., \& Kang, C. B. Relaxation therapy for irritable bowel syndrome: A systematic review. Asian Nursing Research,2014, 8(3), 182-192.

17. Park, S.; Han, K. and Kang, C. Relaxation Therapy for Irritable Bowel Syndrome: A Systematic Review. Asian Nursing Research.2014, 8: 182-192.

18. Schumann D, Anheyer D2, Lauche R3, Dobos G2, Langhorst J2, Cramer H . Effect of Yoga in the Therapy of Irritable Bowel Syndrome: A Systematic Review. Clin Gastroenterol Hepatol. 2016 Dec; 14(12):1720-1731.

19. Timmer, A.; Preiss, J.C.; Motschall, E.; Rücker, G.; Jantschek, G.; Moser, G.:Psychological interventions for treatment of inflammatory bowel disease. Cochrane Database Syst. 2011. Rev.

20. Ungaro,R.;Mehandru, S.; Allen, P.; Peyrin-Biroulet, L.andColombel, J.:Ulcerative colitis,2017,389, (10080):1756-1770.

21. Washington, D: Food, Nutrition, Physical Activity, and the Prevention of Cancer: A Global Perspective; World Cancer Research Fund/American Institute for Cancer Research: 2007,

22. Yeh A. ,Wren, A. and Golianu, B. Mind-Body Interventionsfor Pediatric Inflammatory Bowel Disease. Children, 2017, 4, 22.

23. Zeichner, D 23: Relaxation Techniques to Manage IBS Symptoms, 2018. 